\title{
Mitteilungen des Bundesverbandes Deutscher Pathologen e.V.
}

Pathologe 2014 · 35:196-198

DOI 10.1007s00292-014-1938-7

○) Springer-Verlag Berlin Heidelberg 2014
Geschäftsstelle des Bundesverbandes Deutscher Pathologen e.V.

Invalidenstraße 90, 10115 Berlin

Tel. +49(0)030/3088197-0

E-Mail: bv@pathologie.de www.pathologie.de

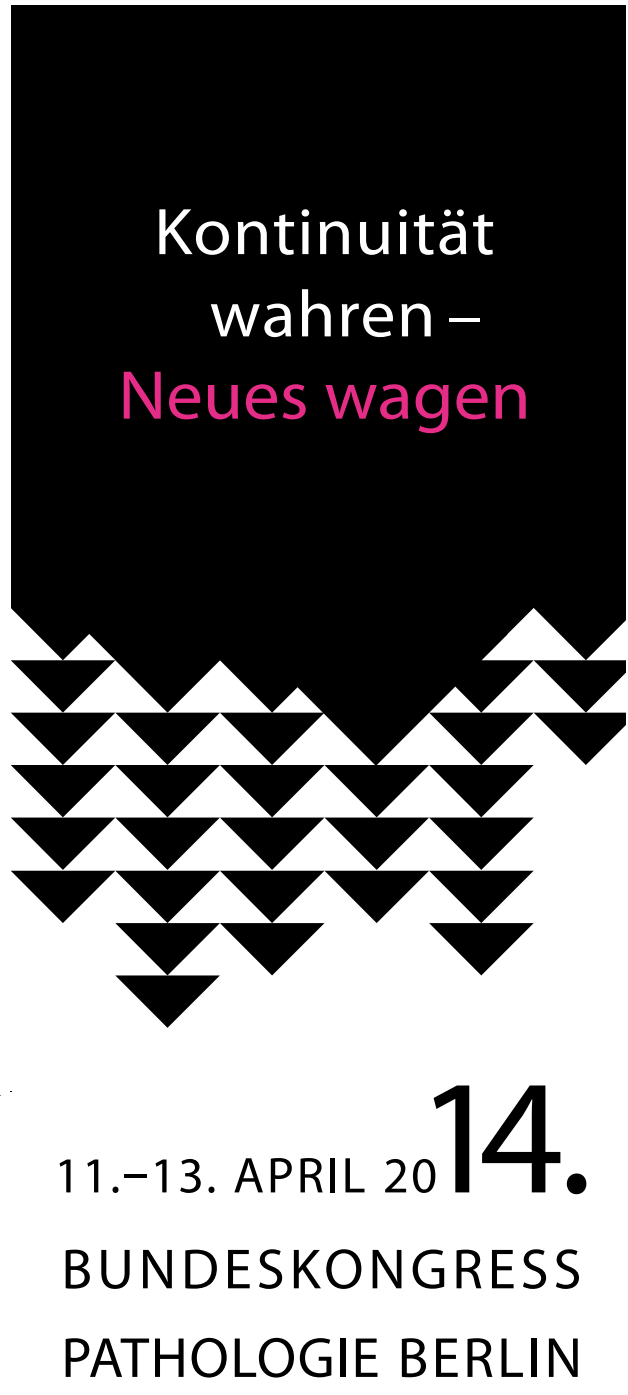

\author{
Maritim Hotel proArte \\ Friedrichstraße 151 | 10117 Berlin
}

BUNDESVERBAND

DEUTSCHER

PATHOLOGEN E.V.
Sehr geehrte Damen und Herren, sehr geehrte Kolleginnen und Kollegen,

die Pathologie hat in Deutschland über die Jahrhunderte hinweg eine bemerkenswerte Kontinuität bewahrt. Sie ist bis heute als Gebiet „ungeteilt“. Sie hat auch über die Zeit alle ihre charakteristischen Merkmale und sogar Methoden behalten. Dies ist ihr nicht deshalb gelungen, weil sie sich nicht verändert hat, sondern gerade weil sie neue Wege gegangen ist. Sie hat sich, nur zum Beispiel, von einem vorwiegend an der Universität zu einem vorwiegend in freiberuflicher Trägerschaft ausgeübten Fach gewandelt und ist dennoch sie selbst geblieben.

Es ist die Frage, ob dem Fachgebiet diese Leistung immer wieder von Neuem gelingt. Wie Sie als Mitglieder sich verhalten, wird dafür ausschlaggebend sein. Thema des Kongresses ist deshalb, neben der exzellenten Fortbildung, auch das Neue, wie die „Bedarfsplanung“ mit ihrem Druck zur Sektorisierung unseres bislang integrativen Fachgebiets oder wie die "Liquid Biopsy“, bei der sich neue Möglichkeiten für die Krankenversorgung abzeichnen. Wir wollen die Strukturen analysieren und prüfen, welche Aktionsmöglichkeiten als Fach und als Individuen wir haben. Tomasi di Lampedusa meinte, es müsse sich alles ändern, damit es bliebe, wie es ist. Wir würden formulieren: Kontinuität wahren - Neues wagen. Kommen Sie mit Ihrer Belegschaft nach Berlin. Wir freuen uns auf Sie.

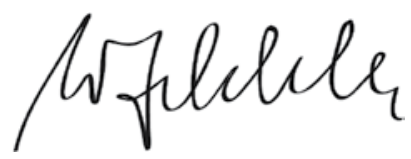

Prof. Dr. med. W. Schlake Präsident

\section{Anmeldung:} www.bundeskongress-pathologie.de 


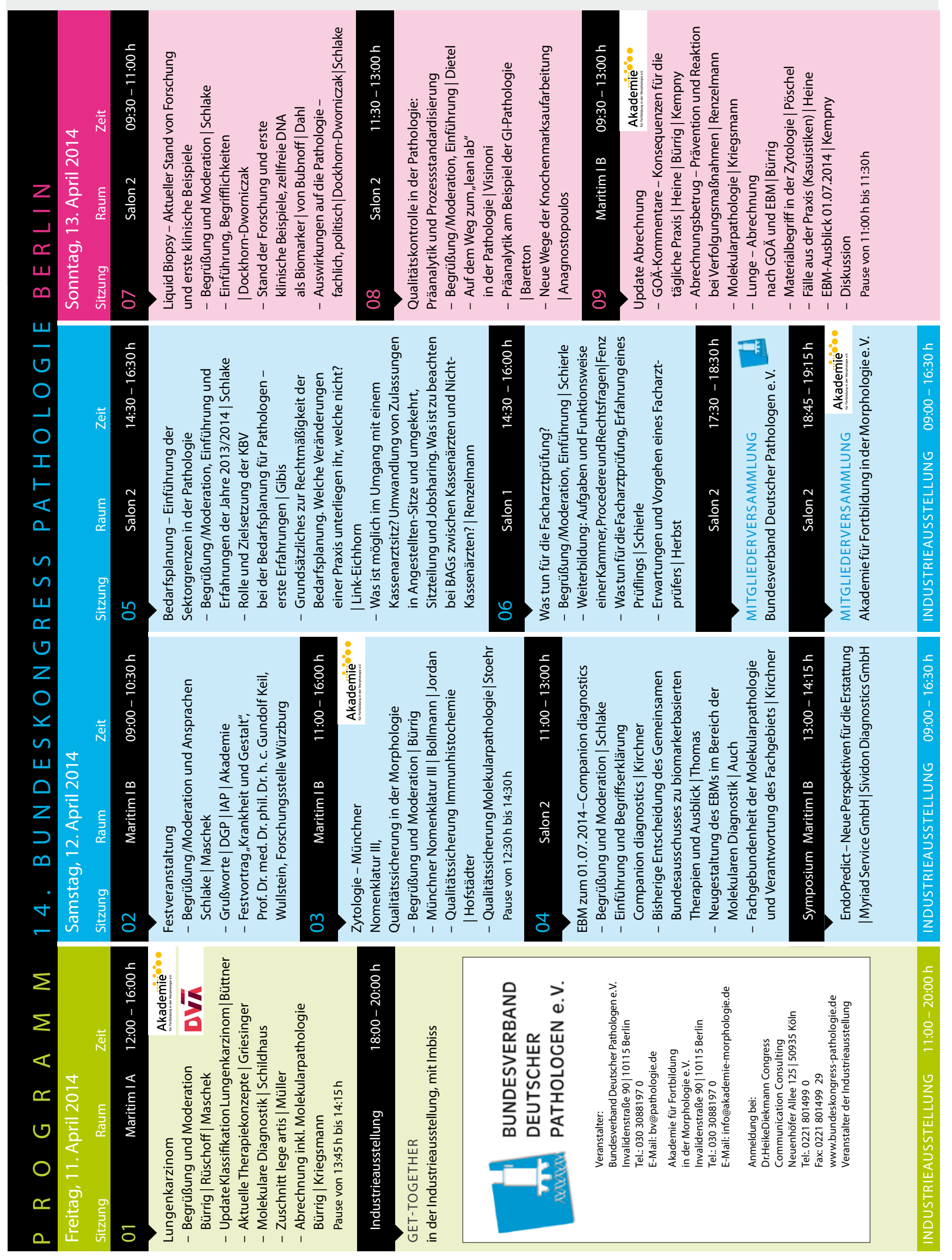




\section{Hier steht eine Anzeige.}

Springer 